PROFESI (Profesional Islam)

Media Publikasi Penelitian; 2017; Volume 15; No 1.

Website: ejournal.stikespku.ac.id

\title{
Pengaruh Terapi Psikoreligius: Dzikir Pada Pasien Halusinasi Pendengaran di RSJD dr. Arif Zainudin Surakarta
}

\author{
Deden Dermawan \\ Program Studi D III Keperawatan Politeknik Kesehatan Bhakti Mulia Sukoharjo \\ Jln Raya Solo Sukoharjo Km 9, Sukoharjo \\ deden_abm@yahoo.co.id
}

Kata Kunci

Dzikir,

Halusinasi

Pendengaran

\begin{abstract}
Abstrak
Pasien dengan halusinasi mengalami ketidakmampuan membedakan rangsangan internal (pikiran) dan rangsangan eksternal (dari luar). Pasien memberikan persepsi atau pendapat tentang lingkungan tanpa objek atau rangsangan yang nyata seperti mendengar suara padahal tidak ada yang sedang berbicara atau mendengar suara. Tanda dan gejala yang dapat diobservasi adalah mendengarkan suara atau kebisingan, dimana suara itu memberi perintah kepada pasien untuk melakukan suatu aktifitas. Tujuan penelitian ini untuk mengetahui pengaruh Dzikir untuk mengatasi pasien yang halusinasi pendengaran. Jenis Penelitian adalah deskriptif kualitatif dengan menggunakan pendekatan proses keperawatan (nursing process). Populasi adalah pasien dengan halusinasi. Teknik sampling: non probalility sampling dengan pendekatan purposive sampling. Sampel penelitian berjumlah 10 responden. Hasil penelitian menunjukan bahwa 5 dari 8 responden mengatakan halusinasi berkurang setelah melakukan dzikir, dan 3 dari 8 responden mengatakan masih mendengar halusinasi setelah melakukan dzikir. Kesimpulan: Dzikir efektif untuk mengurangi halusinasi pendengaran.
\end{abstract}

\section{The Influence Of Psychoreligious Therapy: Dhikr For Auditory Hallucinations' Patients In RSJD dr. Arif Zainudin Surakarta}

\author{
Keywords \\ Dhikr, \\ Auditory \\ Hallucinations
}

\begin{abstract}
Patients with hallucinatory experience inability to distinguish internal and external stimuli. The patient produce perception or opinion about the environment without real existence object or real stimulation. It could be in form of hearing voices when no one was talking or hearing unreal sound. The signs and symptoms that can be observed are patient seems like listening voice or noise which gave orders to the patient to perform activity. Based on the problem above the researcher try to investigate the influence of Dhikr towards auditory hallucinations patients. This research applied descriptive qualitative approach by maximize the nursing process. The population was patient with hallucinations. The sampling techniques was non probalility sampling with purposive sampling approach. The sample of the research were 8 respondents. The results showed that 5 of 8 respondents said their hallucinations was decreased after performing dhikr, whereas 3 of 8 respondents said that they still hear hallucinations after performing dhikr.

Conclusion: Dhikr is effective to reduce auditory hallucinations.
\end{abstract}


PROFESI (Profesional Islam)

Media Publikasi Penelitian; 2017; Volume 15; No 1.

Website: ejournal@stikespku.ac.id

\section{PENDAHULUAN}

Proses globalisasi dan pesatnya kemajuan teknologi informasi memberikan dampak terhadap nilai-nilai sosial dan budaya pada masyarakat. Disisi lain, tidak semua orang mempunyai kemampuan yang sama untuk menyesuaikan dengan berbagai perubahan, serta mengelola konflik dan stres tersebut (Zelika dan Dermawan, 2015).

Penderita gangguan jiwa di dunia diperkirakan akan semakin meningkat seiring dengan dinamisnya kehidupan masyarakat. Hampir 400 juta penduduk dunia menderita masalah gangguan jiwa. Satu dari empat anggota keluarga mengalami gangguan jiwa dan seringkali tidak terdiagnosis secara tepat sehingga tidak memperoleh perawatan dan pengobatan dengan tepat. Di rumah sakit jiwa Indonesia sekitar 70\% mengalami halusinasi yang dialami oleh pasien gangguan jiwa adalah halusinasi suara $(20 \%)$ halusinasi penglihatan $(30 \%)$ dan adalah halusinasi penghidu pengecapan dan perabaan (10\%) (Yosep, 2007).

Halusinasi merupakan terganggunya persepsi sensori seseorang, dimana tidak terdapat stimulus. Tipe halusinasi yang paling sering adalah halusinasi pendengaran (Auditory-Hearing Voices or Sounds), pengelihatan (Visual-Seeing Persons or Things), penciuman (OlfactorySmelling Odors), pengecapan (GustatoryExperiencing Tastes) (Yosep, 2007). Pasien yang mengalami halusinasi disebabkan karena ketidakmampuan pasien dalam menghadapi stressor dan kurangnya kemampuan dalam mengontrol halusinasi (Hidayati, 2014).

Data kunjungan rawat inap Rumah Sakit Jiwa Daerah Surakarta pada bulan Januari-April 2013 didapat 785 orang. Pasien dengan halusinasi menempati urutan pertama dengan angka kejadian $44 \%$ atau berjumlah 345 orang, pasien isolasi sosial menempati urutan kedua dengan angka kejadian $22 \%$ atau berjumlah pasien 173 orang, pasien dengan resiko perilaku kekerasan menempati urutan ketiga dengan angka kejadian $18 \%$ atau berjumlah pasien 141 orang pasien, pasien dengan harga diri rendah menempati urutan keempat dengan angka kejadian $12 \%$ atau berjumlah 94 orang, sedangkan pasien dengan waham, defisit perawatan diri $4 \%$ atau 32 orang. (Sulahyuningsih, 2016).
Terapi psikoreligius Dzikir menurut bahasa berasal dari kata "dzakar" yang berarti ingat. Dzikir juga di artikan "menjaga dalam ingatan". Jika berdzikir kepada Allah artinya menjaga ingatan agar selalu ingat kepada Alla ta'ala. Dzikir menurut syara' adalah ingat kepada Allah dengan etika tertentu yang sudah ditentukan AlQur'an dan hadits dengan tujuan mensucikan hati dan mengagungkan Allah. Menurut Ibn Abbas ra. Dzikir adalah konsep, wadah, sarana, agar manusia tetap terbiasa dzikir (ingat) kepadaNya ketika berada diluar shalat. Tujuan dari dzikir adalah mengagungkan Allah, mensucikan hati dan jiwa, mengagungkan Allah selaku hamba yang bersyukur, dzikir dapat menyehatkan tubuh, dapat mengobati penyakit dengan metode Ruqyah, mencegah manusia dari bahaya nafsu. (Fatihuddin, 2010).

\section{METODE PENELITIAN}

Penelitian ini dilakukan Di Ruang Arjuna RSJD dr. Arif Zainudin Surakarta pada tanggal 30 Maret - 12 April 2017. Penelitian ini menggunakan desain deskriptif kualitatif dengan pendekatan proses keperawatan (nursing proses). Populasi penelitian adalah pasien dengan halusinasi pendengaran, dengan kriteria inklusi pasien dengan diagnosa halusinasi, pasien dengan halusinasi pendengaran dan pasien kooperatif. teknik pengambilan sempel non probalility sampling pendekatan Purposive Sampling. Penelitian menggunakan 8 pasien dengan halusinasi pendengaran. Instrumen penelitian menggunakan Pedoman Wawancara, Lembar Observasi, Perekam, Buku dan alat tulis. Teknik Analisa menggunakan transkrip wawancara dan Trianggulasi Sumber. Peneliti memberikan tindakan Dzikir ketika pasien mendengar suara suara palsu, ketika waktu luang, dan ketika pasien selesai melaksanakan sholat wajib. 
PROFESI (Profesional Islam)

Media Publikasi Penelitian; 2017; Volume 15; No 1.

Website: ejournal.stikespku.ac.id

\section{HASIL DAN PEMBAHASAN \\ 3.1 Karakteristik Subjek Penelitian}

Tabel 1. Karakteristik Subjek Penelitian

\begin{tabular}{|c|c|c|c|c|c|c|}
\hline No & Kode & Nama & Pendidikan & Agama & Usia & Pekerjaan \\
\hline 1 & $\mathrm{R} 1$ & $\mathrm{Tn} . \mathrm{Sr}$ & SMP & Islam & 45 & $\begin{array}{l}\text { Buruh } \\
\text { pabrik }\end{array}$ \\
\hline 2 & $\mathrm{R} 2$ & Tn. S & SD & Islam & 52 & Petani \\
\hline 3 & R3 & Sdr. WA & SMA & Islam & 35 & $\begin{array}{l}\text { Pengang- } \\
\text { guran }\end{array}$ \\
\hline 4 & $\mathrm{R} 4$ & Tn. AS & SMP & Islam & 41 & $\begin{array}{l}\text { Buruh } \\
\text { pabrik }\end{array}$ \\
\hline 5 & R5 & Tn. WR & SMP & Islam & 47 & swasta \\
\hline 6 & R6 & Sdr. WW & SMA & Islam & 32 & $\begin{array}{l}\text { Pengang- } \\
\text { guran }\end{array}$ \\
\hline 7 & R7 & Sdr. MS & SMP & Islam & 22 & $\begin{array}{l}\text { Pengang- } \\
\text { guran }\end{array}$ \\
\hline 8 & $\mathrm{R} 8$ & Tn. SJ & SMA & Islam & 49 & Swasta \\
\hline
\end{tabular}

\subsection{Pengkajian}

Pengkajian dari proses keperawatan bertujuan mengumpulkan informasi atau data tentang klien, untuk mengidentifikasi, mengenali masalah-masalah, kebutuhan kesehatan dan keperawatan klien, baik fisik, mental, sosial, dan lingkungan. Pengambilan data melalui pengkajian dengan mengamati (observasi), wawancara, dan studi dokumentasi. Metode yang digunakan untuk mengumpulkan data tentang pasien antara lain dengan menggunakan: komunikasi (wawancara), pengamatan (observation), pemeriksaan fisik dan studi kasus (Dermawan, 2012).

Peneliti melakukan pengkajian mengenai halusinasi kepada 8 responden dengan melakukan observasi rata - rata klien mengalami tanda dan gejala yang sama yaitu mengarahkan telinga ke arah tertentu, gelisah, terlihat terganggu, marah tanpa sebab, mencoba berinteraksi dengan lingkungan, tidak berdaya, sering menangis sendiri, tertawa sendiri. Hal ini sejalan dengan pendapat yang dikemukakan oleh Direja (2011) tanda dan gejala halusinasi adalah pasien sering berbicara atau tertawa sendiri, marah-marah tanpa sebab, mengarahkan telinga ke arah tertentu, menutup telinga, mendengar suara atau kegaduhan. Mendengar suara yang mengajak pasien bercakap-cakap, mendengar suara yang menyuruh melakukan sesuatu yang berbahaya. Wawancara dari 8 responden mengatakan mendengar suara palsu, sebagian besar suara palsu tersebut muncul ketika malam hari, dan dalam keadaan emosi ketika suara palsu tersebut muncul.

Pengkajian dari 8 responden sebanyak 6 responden berusia antara 25-45 tahun, hal itu menyebabkan masalah yang dialami oleh responden akan lebih bervariasi. Penjelasan oleh Pieter dan Namora (2010) bahwa usia dewasa muda berisiko lebih tinggi mengalami gangguan jiwa terutama halusinasi karena pada tahap ini kehidupan penuh dengan stressor, masa dewasa muda mengalami masa ketegangan emosi dan itu berlangsung hingga usia 30-an. Dalam usia tersebut individu akan mudah mengalami ketidakmampuan menghadapi masalah sehingga akan lebih mudah emosi.

Pengkajian permasalahan yang dilakukan kepada 8 responden, sebanyak 5 responden mengatakan faktor yang menyebabkan klien dibawa kerumah sakit adalah terdapat masalah dengan keluarga. Seperti pendapat Yosep (2007) bahwa salah satu peyebab dari masalah halusinasi adalah faktor perkembangan yang terganggu misalnya rendah kontrol dan kehangatan keluarga yang menyebabkan klien tidak mampu mandiri sejak kecil, mudah frustasi, hilang percaya diri dan lebih rentan terhadap stress.

\subsection{Diagnosa Keperawatan}

Diagnosa/perumusan diagnosa adalah mengidentifikasi masalah melalui respon klien, menyelidiki dan menentukan faktor penunjang (penyebab, tanda dan gejala), mengidentifikasi kemampuan pasien dalam mengatasi masalah. Wahid dan Suprapto (2012)

Berdasarkan pengkajian yang telah dilakukan pada 8 responden didapatkan keluhan yang hampir sama antara R1, R2, R3, R4 R5, R6, R7, $\mathrm{R} 8$ yaitu mereka merasa mendengar bisikan yang menyuruh untuk melakukan sesuatu sehingga menuruti halusinasinya, memukul seseorang ketika emosi, mengarahkan telinga ke arah tertentu, sering tertawa sendiri, merasa takut ketika halusinasinya muncul, perubahan pola komunikasi, gelisah. Sehingga dari data tersebut masalah keperawatan gangguan persepsi sensori: pendengaran (auditori).

Hal ini sesuai dengan teori yang diungkapkan oleh Kim et all (2012) batasan karakteristik dari gangguan persepsi sensori: auditori adalah halusinasi, marah, ketakutan, 
PROFESI (Profesional Islam)

Media Publikasi Penelitian; 2017; Volume 15; No 1.

Website: ejournal@stikespku.ac.id

kurang konsentrasi, perubahan pola komunikasi, kegelisahan, respon emosional yang berlebih, perubahan alam perasaan yang cepat.

\subsection{Perencanaan Keperawatan}

Peneliti memilih tindakan aktifitas berbasis realita yang dapat mengalihkan halusinasi pendengaran dengan dzikir seperti yang dikemukakan oleh Bulechek, Butcher, Dochterman (2016). Untuk mengalihkan halusinasi pendengaran yang dialami oleh pasien peneliti menggunakan tekhnik pengalihan dengan cara dzikir, agar responden dapat mengalihkan halusinasi pendengaran yang dialami sehingga pasien merasakan ketentraman jiwa.

Dengan dilakukannya dzikir diharapkan halusinasi pendengaran yang dialami responden akan teratasi dengan tujuan: frekuensi berkurang, durasi berkurang, gejala halusinasi berkurang. Seperti pendapat Fatihuddin (2010) Dzikir adalah menjaga dalam ingatan agar selalu ingat kepada Allah ta'ala. Dzikir dapat menyehatkan tubuh: hidup orang shaleh lebih ceria, tenang, dan seolah-olah tanpa masalah, karena setiap masalah disikapi dengan konsep takwa. Fungsi dari dzikir antara lain dapat mensucikan hati dan jiwa: berdzikir dapat mengingatkan kita kepada Allah dan hanya kepada-Nya kita meminta pertolongan. Karena segala bentuk masalah adalah dari-Nya, dan dengan berdzikir dapat mengingatkan kita agar selalu berfikir positif. Dzikir dapat menyehatkan tubuh: orang-orang yang kurang dzikir, atau konsep hidupya kurang dikembalikan kepada Allah, hidupnya kelihatan super sibuk, tidak ada jeda menikmati hidup, karena prosesi hidupnya dikejar-kejar oleh bayangan material. Dzikir dapat mencegah manusia dari bahaya nafsu: dzikir bertugas sebagai pengendali nafsu, membedakan yang baik dan buruk.

Pendapat ini diperkuat dengan penelitian sebelumnya yang dilakukan oleh Sulahyuningsih (2016) bahwa terapi religius efektif untuk meningkatkan kemampuan mengontrol halusinasi pendengaran. Dengan berdzikir hati seseorang akan lebih tentram, kegiatan terapi religius dzikir dapat menurunkan gejala psikiatrik. Religius mampu mencegah dan melindungi dari penyakit kejiwaan, mengurangi penderitaan, meningkatkan proses adaptasi mengontrol suara-suara yang tidak ada wujudnya seperti halusinasi pendengaran.

\subsection{Pelaksanaan Keperawatan}

Pelaksanaan implementasi keperawatan terdapat pedoman yang harus diperhatikan setiap perawat diantaranya: (a) tindakan yang dilakukan konsisten dengan rencana dan terjadi setelah validasi rencana tersebut, (b) ketrampilan interpersonal, intelektual, dan teknis dilakukan dengan kompeten dan efisien di lingkungan yang sesuai, (c) keamanan fisik dan psikologis klien dilindungi, (d) dokumentasi tindakan dan respons klien dicantumkan dalam catatan perawatan kesehatan dan rencana asuhan (Dermawan, 2012).

Peneliti melakukan implementasi di Ruang Arjuna sebanyak 3-8 pertemuan. Halusinasi yang didengar oleh pasien berbeda - beda waktu nya. Berdasar hasil observasi pasien melakukan dzikir ketika mendengar suara palsu, ketika sedang sendiri, dan setelah sholat. Peneliti meminta klien untuk melakukan dzikir secara mandiri setelah sholat magrib, isya dan shubuh. Dzikir juga dilakukan secara bantuan, diingatkan oleh peneliti dan dapat dilakukan secara mandiri. Responden melakukan dzikir dengan mengucapkan lafal sebagai berikut: Subhanallah, Alhamdulilah, Allahuakbar, Lailahaillallah, bismilahirohmanirohim. Pendapat Fatihuddin (2010) waktu shubuh adalah waktu yang mulia untuk urusan riski, waktu pagi sampai dhuhur adalah waktu yang baik untuk berkah rizki, waktu maghrib baik dilakukan dzikir pada waktu keheningan malam mampu melepaskan gelombang meta rohaniah sangat tajam sehingga gelora di hati semakin cepat menghadirkan keesaan Allah.

\subsection{Evaluasi Keperawatan}

Evaluasi penelitian ini dengan menentukan perkembangan kesehatan klien, untuk menilai efektifitas, efisiensi, dan produktifitas dari tindakan keperawatan yang telah diberikan, untuk menilai pelaksanaan asuhan keperawatan, mendapatkan umpan balik, sebagai tanggung jawab dan tanggung gugat dalam pelaksanaan pelayanan keperawatan (Dermawan, 2012).

Hasil perbandingan tersebut peneliti mendapatkan hasil dari 8 responden sebanyak 5 responden merasakan tanda dan gejala halusinasi berkurang, merasa lebih tenang. Sebanyak 3 responden tidak merasakan mengalami perubahan, 2 responden sedang berada dalam fase yang menyenangkan dan 1 responden dalam 
fase yang menjijikan. Hal ini sesuai teori yang dijelaskan oleh Sulahyuningsih (2016) fase comforting yaitu fase menyenangkan. Klien mengalami stres, cemas, perasaan perpisahan, rasa bersalah, kesepian yang memuncak, dan tidak dapat diselesaikan. Klien tersenyum atau tertawa yang tidak sesuai, menggerakkan bibir tanpa suara, pergerakan mata cepat, respons verbal yang lambat jika sedang asyik dengan halusinasinnya dan suka menyendiri. Pada fase condemming atau ansietas berat yaitu halusinasi menjadi menjijikkan. Pengalaman sensori menjijikkan dan menakutkan, kecemasan meningkat, melamun, dan berpikir sendiri jadi dominan. Mulai dirasakan ada bisikan yang tidak jelas. Klien tidak ingin orang lain tahu, dan ia tetap dapat mengontrolnya. Meningkatnya tanda-tanda sistem saraf otonom seperti peningkatan denyut jantung dan tekanan darah. Klien asyik dengan halusinasinya dan tidak bisa membedakan realitas.

\section{SIMPULAN}

Hasil pengkajian yang dilakukan kepada 8 responden mengenai halusinasi adalah yang dirasakan oleh responden umumnya memiliki ciri-ciri yang sama yaitu mengarahkan telinga ke arah tertentu, sering mendengar suara palsu, emosi ketika mendengar suara palsu tersebut, merasa terganggu, tidak berdaya, tertawa sendiri, menangis tanpa sebab. Biasanya penderita halusinasi mendengar suara palsu ketika malam hari.

Diagnosa Keperawatan yang muncul pada 8 responden adalah gangguan persepsi halusinasi: auditori. Perencanaan Keperawatan untuk diagnosa keperawatan gangguan persepsi sensori: auditori yaitu: melibatkan klien dalam aktifitas berbasis realitas yang mungkin mengalihkan perhatian dari halusinasi (dzikir).

Pelaksanaan Keperawatan dilakukan 3-8 hari sejak 30 Maret - 15 April. Implementasi yang dilakukan kepada 8 responden dengan melakukan dzikir setiap waktu luang, ketika klien mendengar suara palsu dan ketika setelah sholat. Responden mengucapkan lafal dzikir: Subhanallah, Alhamdullilah, Allahuakbar, Lailaha illallah, bismilahirohmanirohim.

Perkembangan 8 responden setelah diberikan tindakan selama 2 minggu sebagai evaluasi dalam tindakan keperawatan berdasarkan masalah keperawatan sebagai berikut: dari 8 responden sebanyak 5 responden mengatakan halusinasi berkurang setelah melakukan dzikir, dan 3 responden lainnya tidak mengalami perubahan.

\section{REFERENSI}

Bulechek, G.M., Butcher, H \& Dochterman, J M. 2016. Nurshing Intervention Classification (NIC) teen edition. United States of America. Elsevier

Dalami, E. 2009. Asuhan Keperawatan Klien Dengan Gangguan Jiwa. Jakarta: Trans Info Media.

Dermawan, D. 2012. Proses Keperawatan Penerapan Konsep dan Kerangka Kerja. Yogyakarta: Gosyen Publishing

Direja, A.D.S. 2011. Buku Ajar Asuhan Keperawatan Jiwa. Yogyakarta: Nuha Medika.

Fatihuddin. 2010. Tentramkan Hati Dengan Dzikir. Delta Prima Press.

Kim M.J, Gertrude K. McFarland, Audrey M. Mclane. 2006. Diagnosa Keperawatan (Poceket Guide to Nursing Diagnosa). Jakarta: EGC.

Pieter Z.H dan Namora. 2010. Pengantar Psiokologi Dalam Keperawatan. Jakarta: Kencana

Sulahyuningsih, E. 2016. Pengalaman Perawat Dalam Mengimplementasikan Strategi Pelaksanaan Tindakan Keperawatan Pada Pasien Halusinasi Di Rumah Sakit Jiwa Daerah Surakarta. Jurnal Keperawatan Jiwa. Http.eprints.ums.ac.id/40858/

Wahid, A dan Suprapto, I. 2012. Dokumentasi Proses Keperawatan. Yogyakarta: Nuha Medika

Yosep, I. 2007. Keperawatan Jiwa. Bandung: PT Refika Aditama.

Zelika, A.A dan Dermawan, D. 2015. Kajian Asuhan Keperawatan Jiwa Halusinasi Pendengaran Pada Sdr.R di Ruang Nakula Rsjd Surakarta. Jurnal Kepera$\begin{array}{llll}\text { watan Jiwa. } 12 & \text { (2). 8-15. }\end{array}$ www.ejournal.stikespku.ac.id. 